\title{
RESEARCH
}

\section{Vitamin D-deficiency rickets among children in Canada}

\author{
Leanne M. Ward MD, Isabelle Gaboury MSc, Moyez Ladhani MD, Stanley Zlotkin MD PhD
}

$\infty \quad$ See related article page 69

\section{ABSTRACT}

Background: Based on regional and anecdotal reports, there is concern that vitamin D-deficiency rickets is persistent in Canada despite guidelines for its prevention. We sought to determine the incidence and clinical characteristics of vitamin D-deficiency rickets among children living in Canada.

Methods: A total of 2325 Canadian pediatricians were surveyed monthly from July 1,2002 , to June 30,2004 , through the Canadian Paediatric Surveillance Program to determine the incidence, geographic distribution and clinical profiles of confirmed cases of vitamin D-deficiency rickets. We calculated incidence rates based on the number of confirmed cases over the product of the length of the study period ( 2 years) and the estimates of the population by age group.

Results: There were 104 confirmed cases of vitamin Ddeficiency rickets during the study period. The overall annual incidence rate was 2.9 cases per 100000 . The incidence rates were highest among children residing in the the north (Yukon Territory, Northwest Territories and Nunavut). The mean age at diagnosis was 1.4 years (standard deviation [SD] 0.9, min-max 2 weeks-6.3 years). Sixty-eight children $(65 \%)$ had lived in urban areas most of their lives, and 57 (55\%) of the cases were identified in Ontario. Ninety-two ( $89 \%)$ of the children had intermediate or darker skin. Ninety-eight ( $94 \%$ ) had been breast-fed, and 3 children (2.9\%) had been fed standard infant formula. None of the breast-fed infants had received vitamin D supplementation according to current guidelines (400 IU/d). Maternal risk factors included limited sun exposure and a lack of vitamin D from diet or supplements during pregnancy and lactation. The majority of children showed clinically important morbidity at diagnosis, including hypocalcemic seizures (20 cases, 19\%).

Interpretation: Vitamin D-deficiency rickets is persistent in Canada, particularly among children who reside in the north and among infants with darker skin who are breastfed without appropriate vitamin D supplementation. Since there were no reported cases of breast-fed children having received regular vitamin D (400 IU/d) from birth who developed rickets, the current guidelines for rickets prevention can be effective but are not being consistently imple- mented. The exception appears to be infants, including those fed standard infant formula, born to mothers with a profound vitamin D deficiency, in which case the current guidelines may not be adequate to rescue infants from the vitamin D-deficient state.

Une version française de ce résumé est disponible à l'adresse www.cmaj.ca/cgi/content/full/I77/2/I6I/DCI

\section{CMAJ 2007;177(2):16I-6}

Early release, published at www.cmaj.ca on June 28, 2007.

$\mathrm{V}$ itamin D deficiency has been a long-standing public health issue. This condition was first described in association with skeletal deformities by Glisson and colleagues during the mid-I7th century in London, England. With the discovery of the therapeutic benefit of codliver oil, sunshine, vitamin D supplements and fortified dairy products, attention to vitamin $\mathrm{D}$ in health and disease has waxed and then waned. Despite numerous preventive strategies, vitamin D deficiency has remained a global health problem among children. Developed countries such as Canada, Australia, the United Kingdom and the United States have not been exempt from this problem. ${ }^{1-4}$

Vitamin D is critical for skeletal development and cellular function because of its effect on calcium homeostasis by promoting intestinal calcium absorption. The main source of vitamin $D$ is cutaneous synthesis after exposure to ultraviolet $B$ rays. If sun exposure is limited because of northern latitude, darker skin, sun block or lifestyle choice, vitamin D levels can be maintained through the intake of supplements and foods that contain vitamin D (either naturally or fortified). A severe vitamin D deficiency impairs mineralization of bone tissue (causing osteomalacia) and of growth plates (manifesting as rickets). Other

\footnotetext{
From the Department of Pediatrics (Ward), Children's Hospital of Eastern Ontario, University of Ottawa, Ottawa, Ont.; the Chalmers Research Group (Gaboury), Children's Hospital of Eastern Ontario Research Institute, University of Ottawa, Ottawa, Ont.; the Department of Pediatrics (Ladhani), Hamilton Health Sciences Centre, McMaster Children's Hospital, McMaster University, Hamilton, Ont.; the Departments of Paediatrics, Nutritional Sciences and Public Health Sciences and the Centre for International Health (Zlotkin), University of Toronto, Ont.; and the Division of Gastroenterology, Hepatology and Nutrition, and the Child Health and Evaluative Sciences program (Zlotkin), The Hospital for Sick Children, Toronto, Ont.
} 
clinical manifestations during childhood include hypocalcemic seizures, fractures, lower-limb deformities, abnormal dentition and delayed developmental milestones.

In Canada and the United States, commercial fluid dairy products (excluding yogurt drinks) are fortified with vitamin D through regulated public health policy in accordance with published guidelines. ${ }^{5}$ Human milk, the ideal fluid source for infants in the first year of life, is not a rich source of vitamin D. ${ }^{6}$ In view of this, Health Canada ${ }^{7}$ and the Canadian Paediatric Society ${ }^{8}$ recommend that, for the prevention of rickets, Canadian infants and children receive Io $\mu \mathrm{g}$ (400 IU) of vitamin $\mathrm{D}$ per day through either diet or supplementation.

Despite these guidelines and public health measures, a number of regional studies ${ }^{1,9-12}$ and our own clinical experience suggested that vitamin $\mathrm{D}$-deficiency rickets is a persistent problem among infants and children in Canada. The purpose of this study was to determine the incidence of vitamin D-deficiency rickets in Canada through the Canadian Paediatric Surveillance Program, a national disease surveillance network that provides data obtained through monthly written contact with pediatricians and pediatric subspecialists across the country. In addition to obtaining incidence data, we sought to determine the clinical and demographic profile of the infants and children identified as having vitamin Ddeficiency rickets over the 2-year study period.

\section{Methods}

\section{Study design}

A total of 2325 pediatricians and pediatric subspecialists in active clinical practice were surveyed from July I, 2002, to June 30, 2004, through the established network of the Canadian Paediatric Surveillance Program, a joint initiative of the Canadian Paediatric Society and the Public Health Agency of Canada. Participants were mailed a monthly check-off form asking whether or not they had identified any new cases of vitamin D-deficiency rickets. If a positive response was received, a detailed reporting form was sent to obtain anonymous information confirming that the case criteria were met and to obtain supporting data to capture the demographic and medical profiles of the confirmed cases.

The study was approved by the Research Ethics Boards at the Children's Hospital of Eastern Ontario (University of Ottawa, Ottawa, Ont.), McMaster Health Sciences Centre (McMaster University, Hamilton, Ont.) and the Hospital for Sick Children (University of Toronto, Toronto, Ont.).

\section{Eligibility criteria}

The absolute inclusion criteria were as follows: children up to and including 18 years of age who had a low serum level of 25-hydroxyvitamin D (less than $27.5 \mathrm{nmol} / \mathrm{L}$ ) based on local laboratory reports. Patients with a 25 -hydroxyvitamin D level above $27.5 \mathrm{nmol} / \mathrm{L}$ were excluded if they had isolated dietary calcium-deficiency rickets. Patients were also excluded if they had not received vitamin D therapy before 25 -hydroxyvitamin D levels were tested; if they had received vitamin D therapy before testing, they were included only if it was possible to confirm that they had been receiving the age-appropriate di- etary reference intake of calcium, ${ }^{13}$ either through diet or supplementation.

The exclusion criteria were as follows: vitamin Ddeficiency rickets associated with an underlying disease such as fat malabsorption, liver disease, renal insufficiency and illnesses necessitating total parenteral nutrition; vitamin D deficiency secondary to a heritable disorder of vitamin D metabolism, including $\mathrm{I}-\alpha$-hydroxylase deficiency and vitamin $\mathrm{D}$ receptor defects; or hypophosphatemic rickets (hypophosphatemia as the main cause of the rickets, not vitamin Ddeficiency rickets with secondary hyperparathyroidism causing hyperphosphaturia).

\section{Supporting clinical data}

Radiographic signs of rickets were supportive of the diagnosis but were not required for inclusion (young infants may not show radiographic changes caused by vitamin D deficiency early in the course of the condition). Rickets was diagnosed by radiographic signs at the wrist or knee, as determined by a radiologist at the patient's local institution.

The serum levels of calcium, phosphate, alkaline phosphatase, parathyroid hormone and I,25-dihydroxyvitamin D were recorded, if available, to facilitate case confirmation.

Skin colour was determined by the pediatrician's subjective assessment, and ethnic background was recorded as reported by the parents. Additional recorded information included the mother and child's history of calcium and vitamin D intake and sun exposure, and whether the child's family had immigrated to Canada.

\section{Statistical analysis}

Descriptive results are expressed as percentages, means and standard deviations (SDs), and median and minimum to maximum values as appropriate. We calculated the incidence rates based on the number of confirmed cases over the product of the length of the study period ( 2 years) and the estimates of the population by age group ( $<\mathrm{I}, \mathrm{I}-2,>2-7$ years) obtained from Statistics Canada. ${ }^{14}$ All incidence rates are expressed as annual rates. Homogeneity across rates was assessed with a $\chi^{2}$ test. Heterogeneous rates across provinces were pooled using a Poisson regression model. Rates and 95\% confidence intervals (CIs) are presented for the pooled results.

\section{Results}

\section{Incidence of vitamin D-deficiency rickets}

Between July 2002 and June 2004, there were 150 reports of rickets among children living in Canada. Of these, I04 were confirmed to be due to vitamin D deficiency, 30 were duplicate cases, and $\mathrm{i} 6$ were excluded because they did not meet the case definition. The mean response rate per month among participating pediatricians over the study period was $84.5 \%$. The incidence rates for confirmed cases of vitamin $\mathrm{D}$-deficiency rickets are presented in Table $\mathrm{I}$. The overall annual incidence rate was 2.9 cases per 100000 (95\% CI 2.2-3.7). There was no significant evidence of heterogeneity in the rates across provinces in the youngest group ( $<$ I years, $p=0.16)$. Significant heterogeneity was observed in the other 
2 age groups (I-2 years, $>2-7$ years, $p<0.00$ I for both groups). For children older than I year, the incidence rates were highest among those in the north (Yukon Territory, Northwest Territories and Nunavut). Whether this observation is the result of later diagnosis of features that were present in infancy could not be ascertained from the information available.

\section{Clinical and demographic profile of confirmed cases}

The mean number of cases reported per month from Feb. I to May 3I each year was I4.0 (SD I.9), as compared with 6.9 cases (SD 2.I) per month between June I and Jan. 3I each year. Of the I03 cases for whom data on skin colour were available, $92(89 \%)$ were intermediate or darker skinned (Table 2), and II (Io\%) were fair skinned. Of cases, 33\% (34) were Black, I4\% (I4) Middle Eastern, I3\% (I3) First Nations, I2\% (I2) Inuit, II\% (II) Caucasian, I\% (I) Latin American and I\% (I) Asian (ethnic background not reported for $15 \%$ [I8] of cases). Nearly two-thirds $(67,65 \%)$ of the cases had lived in Canadian cities most of their lives $(26$ [24\%] in Toronto; 15
[ $14 \%]$ in Ottawa; 7 [7\%] in Calgary; 4 [4\%] in Edmonton; 2 [2\%] each in Winnipeg, Hamilton, Ont., Windsor, Ont., Kitchener, Ont., London, Ont.; I [I\%] each in Halifax, Saint John, NB, Sherbrooke, Que., Medicine Hat, Alta., and Nanaimo, BC). The remaining cases were identified as living in rural Canada. The families of 25 (24\%) of the cases had immigrated to Canada prior to diagnosis.

Physicians reported that 98 cases $(94 \%)$ were breast-fed at the time of diagnosis; 3 cases had been exclusively fed standard infant formula, and feeding status was not reported for 3 cases. The mean duration of breast-feeding was I3.8 (SD 5.7) months. Most cases ( $87 \%$ [90/I04]) had not received vitamin D supplementation before diagnosis. In the remaining I4 cases ( $13 \%)$, supplementation had either not been reported on the case-report form or had been unreliably administered by caregivers before diagnosis. There were no reports of children who had rickets despite having received the recommended amount of vitamin D supplementation (400 IU/d). The 3 infants who had been fed an adequate amount of standard cow's milk-based formula for normal growth before the rickets diagnosis were of First Nations background and pre-

Table 1: Incidence of vitamin D-deficiency rickets in Canada from July 1, 2002, to June 30, 2004, by province or territory and age group

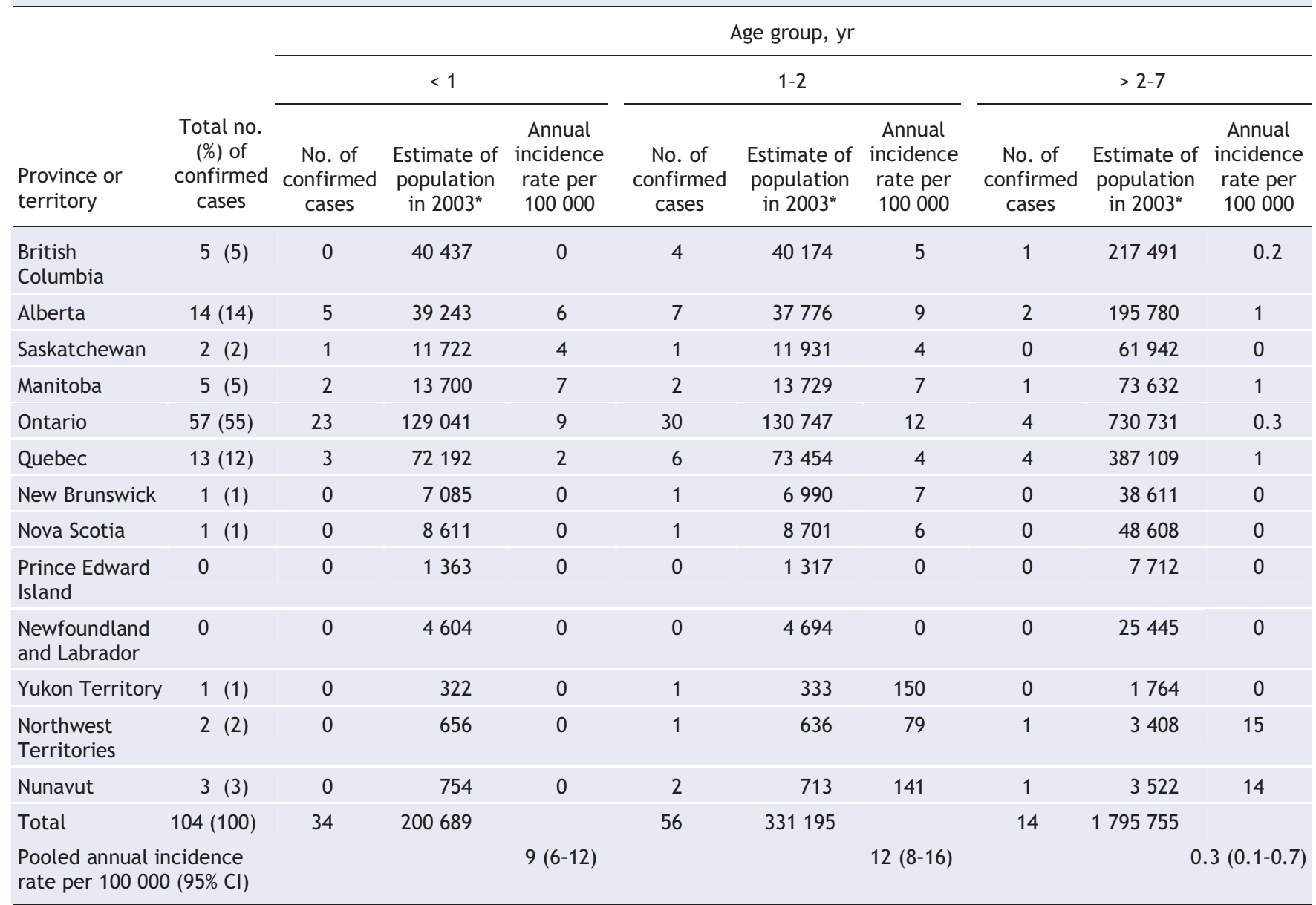

Note: $\mathrm{Cl}=$ confidence interval.

*Estimates of the population by age groups are based on results of the 2000 census, adjusted for net undercoverage and for the estimated population growth that occurred from 2000 to the end of 2003 . The estimates were compiled based on the age (in years) of children registered in the census at last birthday. The year 2003 was chosen for the estimate of the population because it represents the study midpoint. 
sented within 5-50 days of life with hypocalcemic seizures. In these cases, maternal vitamin $\mathrm{D}$ levels were reported to be critically low (less than $27.5 \mathrm{nmol} / \mathrm{L}$ ).

The clinical presentation of the cases is shown in Table 3. Hypocalcemic seizures were more frequent among infants than among older children, whereas older children were more likely than infants to present with skeletal deformities. Overall, radiographic evidence of rickets was present in $93 \%$ (87/94) of the cases. The mean age of children with vitamin D deficiency but without radiographic signs of rickets was 0.68 (SD 0.36) years. Before or soon after initiation of vitamin D therapy, the mean alkaline phosphatase level was I237 (SD I05I, median 923, min-max I86-6067) U/L. The 25-hydroxyvitamin D level before or within the first few weeks of treatment was available for $75 \%$ (78/104) of the confirmed cases, and the median value was 15 (min-max I-84) nmol/L.

\section{Maternal characteristics}

The mean maternal age at the time of delivery was 28 (SD 6.2, min-max 15-39) years. Twenty-one mothers (20\%) wore a head covering during and following pregnancy. During pregnancy, $\mathrm{I}_{3}$ (12.5\%) of the mothers were documented as having

Table 2: Characteristics of confirmed cases of vitamin D-deficiency rickets in Canada from July 1, 2002, to June 30, 2004

\begin{tabular}{|c|c|c|c|c|}
\hline Characteristic & \multicolumn{3}{|c|}{ Age group, yr; no. (\%) of cases } & $\begin{array}{l}\text { Total } \\
\text { no. (\%) cases }\end{array}$ \\
\hline Breast-fed ${ }^{*}$ & $31(91)$ & $55(98)$ & $12(86)$ & $98(94)$ \\
\hline Intermediate or darker skin & $31(91)$ & 48 (86) & $13(93)$ & 92 (89) \\
\hline Breast-fed & 0 & 3 (75) & $1(100)$ & $4(80)$ \\
\hline Intermediate or darker skin & 0 & $4(100)$ & $1(100)$ & $5(100)$ \\
\hline Immigrant to Canada & 0 & 1 (25) & 0 & $1(20)$ \\
\hline Alberta & $n=5$ & $n=7$ & $n=2$ & $n=14$ \\
\hline Saskatchewan, Manitoba & $n=3$ & $n=3$ & $n=1$ & $n=7$ \\
\hline Breast-fed & $2(67)$ & $3(100)$ & 0 & $5(71)$ \\
\hline Intermediate or darker skin & $2(67)$ & $3(100)$ & $1(100)$ & $6(86)$ \\
\hline Immigrant to Canada & 0 & 0 & $1(100)$ & $1(14)$ \\
\hline Ontario & $n=23$ & $n=30$ & $n=4$ & $n=57$ \\
\hline Breast-fed & $22 \quad(96)$ & $30(100)$ & $3(75)$ & $55(96)$ \\
\hline Intermediate or darker skin & $23(100)$ & $26(87)$ & $4(100)$ & $53(93)$ \\
\hline Immigrant to Canada & $8 \quad(34)$ & $8(27)$ & $2(50)$ & $18(32)$ \\
\hline Quebec & $n=3$ & $n=6$ & $n=4$ & $n=13$ \\
\hline Intermediate or darker skin & 0 & 0 & 0 & 0 \\
\hline Immigrant to Canada & 0 & 0 & 0 & 0 \\
\hline $\begin{array}{l}\text { Yukon Territory, Northwest } \\
\text { Territories and Nunavut }\end{array}$ & $n=0$ & $n=4$ & $n=2$ & $n=6$ \\
\hline Breast-fed & 0 & $4(100)$ & $2(100)$ & $6(100)$ \\
\hline Intermediate or darker skin & 0 & $4(100)$ & $2(100)$ & $6(100)$ \\
\hline Immigrant to Canada & 0 & 0 & 0 & 0 \\
\hline
\end{tabular}

*Breast-feeding was the most frequent risk factor. Three children had exclusively received standard infant formula. 
received vitamin D supplementation. Following delivery, 5 (5\%) of the mothers received supplementation. The majority of the mothers $(79,76 \%)$ did not drink milk pre- or postnatally.

\section{Interpretation}

Despite recommendations from Health $\mathrm{Canada}^{7}$ and the Canadian Paediatric Society, ${ }^{8}$ there has been a failure to prevent vitamin $D$ deficiency in Canada, resulting in clinically important skeletal and systemic morbidity and an overall annual incidence rate of vitamin D-deficiency rickets of 2.9 per Ioo 000 children. This condition was most frequently observed among darker-skinned, breast-fed infants and children, with the highest incidence among children from north (Yukon Territory, Northwest Territories and Nunavut). Maternal characteristics (skin colour, lack of sun exposure and inadequate vitamin D intake or supplementation) were contributing factors.

Rickets in children has been identified as a persistent global health concern largely through published case series, retrospective chart reviews at local institutions and crosssectional studies. ${ }^{1,4,15-18}$ Recent reports have noted cases not only from regions with more limited sunshine, such as New Zealand, ${ }^{19}$ the United Kingdom ${ }^{20}$ and the United States, ${ }^{18}$ but also from sunnier regions such as Africa, ${ }^{21}$ Saudi Arabia ${ }^{22}$ and Australia. ${ }^{4}$ Lack of sunlight exposure (even at low latitudes), breast-feeding, darker skin and recent immigration are the most common risk factors in these reports. In the United Kingdom (West Midlands), Callaghan and colleagues, in a prospective surveillance study lasting I year, found an overall vitamin D deficiency annual incidence rate of 7.5 per 100000 children, with children of black African or African-Caribbean ethnic background having the highest incidence rates. ${ }^{23}$ As in our study, the north-south gradient has been shown to be a factor, with more Asian children living in northern Scotland than in southern Scotland having rickets. ${ }^{24}$ The question has been raised whether rickets has reemerged in recent years, or whether it has simply remained a persistent problem. In Canada, studies of the systematic prevalence and incidence have not been performed in the same regions at different times. The available evidence suggests that, like observations worldwide, rickets has continued to be an important child health issue in Canada despite simple measures for its prevention.

Breast milk is indisputably the ideal food for infants; however, breast milk typically contains about 25 IU or less vitamin D per litre, ${ }^{6,25}$ which is insufficient for rickets prevention. Although there is evidence that limited sun exposure may prevent rickets in some breast-fed infants, ${ }^{26,27}$ concern over the health risks of sun exposure have led to the recommendation that all breast-fed infants receive supplemental vitamin D (400 IU/d). ${ }^{7,8}$ It is recommended that breast-fed infants who reside above the 55th latitude in Canada or in areas at lower latitudes that have a high incidence of vitamin D deficiency receive $800 \mathrm{IU} / \mathrm{d}$ during the winter months. ${ }^{28}$ In our study, there were no reported cases of rickets among children who were breast-fed and received regular vitamin D (400 IU/d). Our findings suggest that the current guidelines for rickets prevention can be effective but that they are not consistently being implemented.

Babies who drink an adequate amount of infant formula to achieve normal growth typically receive sufficient vitamin D (400 IU per litre of standard commercial formula) to prevent rickets. In our study, however, 3 infants who received enough infant formula to support normal growth manifested rickets in the first few weeks of life. The timing of presentation of these cases suggests that the vitamin D deficiency resulted from insufficient transfer of 25 -hydroxyvitamin $\mathrm{D}$ from the mother to the fetus (which mostly occurs during the third trimester) ${ }^{29,30}$ and that the deficit was too severe to be rescued by vitamin $\mathrm{D}-$ fortified formula. These observations underline the importance of maternal vitamin $\mathrm{D}$ intake during pregnancy (for both breast- and bottle-fed infants) and lactation (for breast-fed infants). In a review of vitamin intake during pregnancy, ${ }^{31}$ Hollis and Wagner proposed that the current guidelines for expectant mothers $(200-400 \mathrm{IU} / \mathrm{d}, 800 \mathrm{IU} / \mathrm{d}$

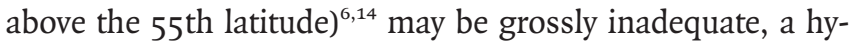
pothesis that is being investigated in clinical trials.

The main limitation of our study is that the monthly surveys were sent only to pediatricians and pediatric subspecialists, but not to family physicians. Vitamin D-deficiency rickets is a condition that can be diagnosed and treated by family doctors, many of whom work in remote regions of Canada. If family physicians had been included, the incidence of rickets would undoubtedly have been increased. In addition, the mean response rate of $85 \%$, although higher than for most mail-out surveys published in medical journals, ${ }^{32}$ may have also decreased the number of cases identified.

Table 3: Clinical presentation of cases of vitamin D-deficiency rickets reported between July 1, 2002, and June 30, 2004

\begin{tabular}{|c|c|c|c|c|}
\hline \multirow[b]{2}{*}{ Characteristic } & \multicolumn{4}{|c|}{ Age group, yr; no. (\%) of cases* } \\
\hline & $\begin{aligned}< & 1 \\
n & =34\end{aligned}$ & $\begin{array}{c}1-2 \\
n=56\end{array}$ & $\begin{array}{l}>2-7 \\
n=14\end{array}$ & $\begin{array}{c}\text { Total } \\
n=104\end{array}$ \\
\hline Age, yr, mean (SD) & $0.6(0.3)$ & $1.4(0.3)$ & $3.2(1.3)$ & $1.4(1)$ \\
\hline Male & $22(65)$ & $28(50)$ & $4(29)$ & $54(52)$ \\
\hline Skeletal deformity & $8(24)$ & $26(46)$ & $10(71)$ & $44(42)$ \\
\hline $\begin{array}{l}\text { Hypocalcemic } \\
\text { seizures }\end{array}$ & $16(47)$ & $4(7)$ & 0 & 20 (19) \\
\hline $\begin{array}{l}\text { Delayed } \\
\text { developmental } \\
\text { milestones }\end{array}$ & $1(3)$ & $10(18)$ & $1(7)$ & $12(12)$ \\
\hline Fractures & $3(9)$ & $6(11)$ & $2(14)$ & $11(11)$ \\
\hline $\begin{array}{l}\text { Incidental finding } \\
\text { of rickets }\end{array}$ & $3(9)$ & $3(5)$ & $1(7)$ & $7(7)$ \\
\hline Failure to thrive & $2(6)$ & $3(5)$ & 0 & $5(5)$ \\
\hline Irritability & 0 & $1(2)$ & 0 & $1(1)$ \\
\hline Limp & 0 & $1(2)$ & 0 & $1(1)$ \\
\hline Weakness & 0 & $1(2)$ & 0 & $1(1)$ \\
\hline Not indicated & $1(3)$ & $1(2)$ & 0 & $2(2)$ \\
\hline
\end{tabular}

*Unless specified otherwise. 
Given the failure to prevent vitamin D-deficiency rickets in Canada and the potential for serious morbidity, there is an urgent need for heightened awareness among health care providers and the general public. Attention to maternal vitamin D status during pregnancy and lactation, assessment of the lack of success associated with the implementation of current recommendations and re-evaluation of the current guidelines in high-risk populations (darker-skinned, northern and indigenous mothers and infants) are warranted.

This article has been peer reviewed.

Competing interests: None declared.

Contributors: All authors contributed to the design of the study, data acquisition, and analysis and interpretation of the data, and gave final approval of the version to be published. Leanne Ward independently led the study and drafted the article, and all authors critically reviewed the manuscript for important intellectual content. All investigators had full access to all of the data in the study and take responsibility for the integrity of the data and the accuracy of the data analysis.

Acknowledgements: The Canadian Paediatric Surveillance Program is a joint initiative of the Canadian Paediatric Society and the Public Health Agency of Canada. We thank Dr. Danielle Grenier and the Canadian Paediatric Surveillance Program staff for contacting the pediatricians and for collecting the data, and the clinicians across Canada who took the time to complete the surveys and submit follow-up data. We also thank Colleen White and Maya Scharke, who assisted with data management.

This study was supported by unrestricted educational grants to the Canadian Paediatric Surveillance Program from the Dairy Farmers of Canada and Mead Johnson Nutritionals. These agencies played no role in the design or conduct of the study, the collection, management, analysis, or interpretation of the data, preparation, review or approval of the manuscript. This study was also supported by the Children's Hospital of Eastern Ontario Research Institute. Leanne Ward was supported by a Canadian Institutes for Health Research New Investigator Award and a Canadian Child Health Clinician Scientist Program Award.

\section{REFERENCES}

I. Binet A, Kooh SW. Persistence of vitamin D-deficiency rickets in Toronto in the I99os. Can J Public Health 1996;87:227-30.

2. Bishop N. Rickets today — children still need milk and sunshine. N Engl J Med I999;341:602-4.

3. Rowe PM. Why is rickets resurgent in the USA? Lancet 200I;357:1100.

4. Robinson PD, Hogler W, Craig ME, et al. The re-emerging burden of rickets: a decade of experience from Sydney. Arch Dis Child 2006;91:564-8.

5. Institute of Medicine Food and Nutrition Board; Standing Committee on Use of Dietary Reference Intakes in Nutrition Labeling. Overview of food fortification in the United States and Canada. In: Dietary reference intakes: guiding principles for nutrition labeling and fortification. Washington (DC): National Academies Press 2003. p. 45-55.

6. Nakao H. Nutritional significance of human milk vitamin $\mathrm{D}$ in the neonatal period. Kobe J Med Sci I988;34:I2I-8.

7. Health Canada. Vitamin D supplementation for breastfed infants: 2004 Health
Canada recommendation. Ottawa: Health Canada; 2004. Available: www.hcsc.gc.ca/fn-an/alt_formats/hpfb-dgpsa/pdf/nutrition/vita_d_supp_e.pdf (accessed 2007 May 25).

8. Statement of the Joint Working Group; Canadian Paediatric Society, Dieticians of Canada, Health Canada. Nutrition for healthy term infants. Ottawa: Minister of Public Works and Government Services Canada; i998. Available: www.hc-sc .gc.ca/fn-an/alt_formats/hpfb-dgpsa/pdf/nutrition/infant-nourrisson_e.pdf (accessed 2007 May 25).

9. Haworth JC. Rickets still affects Canadian children. CMAJ I995;I53:740-I.

Io. Lebrun JB, Moffatt ME, Mundy RJ, et al. Vitamin D deficiency in a Manitoba community. Can J Public Health 1993;84:394-6.

II. Moffatt ME. Current status of nutritional deficiencies in Canadian aboriginal people. Can J Physiol Pharmacol 1995;73:754-8.

I2. Wilton P. Cod-liver oil, vitamin D and the fight against rickets. CMAJ I995; I52:1516-7.

I3. Institute of Medicine Food and Nutrition Board; Standing Committee on the Scientific Evaluation of Dietary Reference Intakes. Vitamin D. In: Dietary reference intakes for calcium, phosphorus, magnesium, vitamin $D$ and fluoride. Washington (DC): National Academies Press; 1997. p. 250-87.

I4. Canadian Socio-economic Information Management System (CANSIM). Ottawa: Statistics Canada; 2003.

15. Strand MA, Perry J, Jin M, et al. Diagnosis of rickets and reassessment of prevalence among rural children in northern China. Pediatr Int 2007;49:202-9.

I6. Haworth JC, Dilling LA. Vitamin D-deficient rickets in Manitoba, I972-84. CMAJ I986;I34:237-4I.

I7. Mylott BM, Kump T, Bolton ML, et al. Rickets in the Dairy State. WMJ 2004; I03:84-7.

I8. Weisberg P, Scanlon KS, Li R, et al. Nutritional rickets among children in the United States: review of cases reported between 1986 and 2003. Am J Clin Nutr 2004;80:I697S-705S.

I9. Blok BH, Grant CC, McNeil AR, et al. Characteristics of children with florid vitamin D deficient rickets in the Auckland region in I998. NZ Med J 2000;113:374-6.

20. Shaw NJ, Pal BR. Vitamin D deficiency in UK Asian families: activating a new concern. Arch Dis Child 2002;86:I47-9.

21. Karrar ZA. Vitamin D deficiency rickets in developing countries. Ann Trop Paediatr I998;I8(Suppl):S89-92.

22. Al-Mustafa $\mathrm{ZH}, \mathrm{Al}$-Madan $\mathrm{M}, \mathrm{Al}$-Majid $\mathrm{HJ}$, et al. Vitamin $\mathrm{D}$ deficiency and rickets in the eastern province of Saudi Arabia. Ann Trop Paediatr 2007;27:63-7.

23. Callaghan AL, Moy RJ, Booth IW, et al. Incidence of symptomatic vitamin D deficiency. Arch Dis Child 2006;91:606-7.

24. Henderson JB, Dunnigan MG, McIntosh WB, et al. The importance of limited exposure to ultraviolet radiation and dietary factors in the aetiology of Asian rickets: a risk-factor model. QJ Med 1987;63:413-25.

25. Hollis BW, Roos BA, Draper HH, et al. Vitamin D and its metabolites in human and bovine milk. J Nutr I981;111:1240-8.

26. Specker BL, Valanis B, Hertzberg V, et al. Sunshine exposure and serum 25-hydroxyvitamin D concentrations in exclusively breast-fed infants. J Pediatr I985;I07: 372-6.

27. Greer FR, Marshall S. Bone mineral content, serum vitamin D metabolite concentrations, and ultraviolet B light exposure in infants fed human milk with and without vitamin D2 supplements. J Pediatr I989;II4:204-I2.

28. Canadian Paediatric Society. Vitamin D supplementation in northern Native communities. J Paediatr Child Health 2002;7:459-65.

29. Russell JG, Hill LF. True fetal rickets. BrJ Radiol 1974;47:732-4

30. Moncrieff M, Fadahunsi TO. Congenital rickets due to maternal vitamin D deficiency. Arch Dis Child I974;49:810-I.

3I. Hollis BW, Wagner CL. Nutritional vitamin D status during pregnancy: reasons for concern. CMAJ 2006;174:1287-90.

32. Asch DA, Jedrziewski MK, Christakis NA. Response rates to mail surveys published in medical journals. JClin Epidemiol 1997;50:1129-36.

Correspondence to: Dr. Leanne M. Ward, Rm. 25oH, Research

Institute, Children's Hospital of Eastern Ontario, 4or Smyth Rd., Ottawa ON KIH 8LI; fax 6r3 738 4236; Lward@cheo.on.ca 